\title{
Pengaruh Temperatur Media Pendingin dan Circle Time terhadap Defect Crack Line pada Produk SP 04
}

\section{Haemonetics}

\author{
Surya Ananda Purba, Muhammad Hasan Albana, Nugroho Pratomo Ariyanto \\ Politeknik Negeri Batam \\ Program Studi Teknik Mesin
}

Jl. Ahmad Yani, Kecamatan Batam Kota, Batam 29461, Indonesia

*E-mail: surya.ananda.purba@gmail.com

\begin{abstract}
Abstrak
Temperature dan circle time merupakan bagian yang sangat berpengaruh pada mesin molding injection, produk hasil injection molding sangat ditentukan dari penggunaan temperature media pendingin dan circle time yang digunakan pada saat proses produksi sedang berlangsung. Pengaturan temperature media pendingin sangat dituntut untuk memenuhi penyesuaian dengan meterial yang digunakan pada proses injection molding dan begitu juga dengan faktor circle time pada mesin tersebut dengan circle time dapat memaksimalkan hasil proses injection molding dengan temperature yang bervariasi. Salah satu upaya untuk mengurangi masalah reject crack line pada produk hasil injection molding adalah menyesuaikan temperature media pendingin cetakan (mold) dengan circle time. Penelitian ini bertujuan untuk mengetahui efisiensi penentuan penggunaan temperature media pendingin dan circle time pada proses injection molding pada produk SP 04 Haemonetics dengan menggunakan material ABS TECHNO 330. Perbandingan temperature media pendingin dilakukan dengan variabel perbandingan temperature yaitu $19^{\circ} \mathrm{C}$, $20^{\circ} \mathrm{C}, 21^{\circ} \mathrm{C}, 22^{\circ} \mathrm{C}$ dan $23^{\circ} \mathrm{C}$ serta dengan penyesuain circle time pada setiap proses yaitu perbandingan circle time yaitu 13 detik, 15 detik, 17 detik, 19 detik dan 21 detik. Tetapi pada temperature media pendingin diatas penggunaan normal yaitu pada temperatur diantara $20^{\circ} \mathrm{C}, 21^{\circ} \mathrm{C}, 22^{\circ} \mathrm{C}$ dan $23^{\circ} \mathrm{C}$ reject crack line tidak ditemukan dengan penyesuaian circle time yang berarti pengujian dengan perbandingan temperature media pendingin dan circle time bekerja dengan baik.
\end{abstract}

Kata kunci: ABS TECHNO 330, Temperature dan Circle time, Injection molding.

\begin{abstract}
Abstrack
Temperature and cycle time is a very influential on injection molding machines, injection molding products is determined from the use temperature of the cooling medium and circle time which is used during the production process is underway. The setting temperature of the cooling medium is highly demanded to meet with the adjustment meterial used in the injection molding process and so is the factor of circle time on the machine with a circle time can maximize the results of the injection molding process with varying temperature. One effort to reduce the problem of crack reject line in injection molding products is adjusting the cooling medium temperature molding (mold) with circle time. This study aims to determine the efficiency of the use of the determination of the temperature of cooling medium and circle time in the injection molding process on SP 04 Haemonetics product using ABS material TECHNO 330. Comparison of the cooling medium temperature is done with a variable ratio of temperature that is $19^{\circ} \mathrm{C}, 20^{\circ} \mathrm{C}, 21^{\circ} \mathrm{C}, 22^{\circ} \mathrm{C}$ and $230 \mathrm{C}$, and with a circle adjustment time on every process that comparison circle time is 13 seconds, 15 seconds, 17 seconds, 19 seconds and 21 seconds. But at temperatures above the normal use of the cooling medium at a temperature between $20^{\circ} \mathrm{C}, 21^{\circ} \mathrm{C}, 22^{\circ} \mathrm{C}$ and $23^{\circ} \mathrm{C}$ reject crack line can not be found with a circle adjustment time that means testing the temperature of the cooling medium ratio and circle time worked well.
\end{abstract}

Keywords: ABS TECHNO 330, Temperature and Cycle time, Injection molding. 


\section{Pendahuluan}

Injection moulding adalah mesin yang digunakan untuk mencetak suatu barang dengan material berupa biji plastik dimana menggunakan proses pemanasan terlebih dahulu pada barrel dengan titik didih sesuai material yang digunakan kemudian didinginkan dan dicetak pada ruangan yang disebut sebagai mold (cetakan).

Bagian-bagian injection molding adalah sebagai berikut :

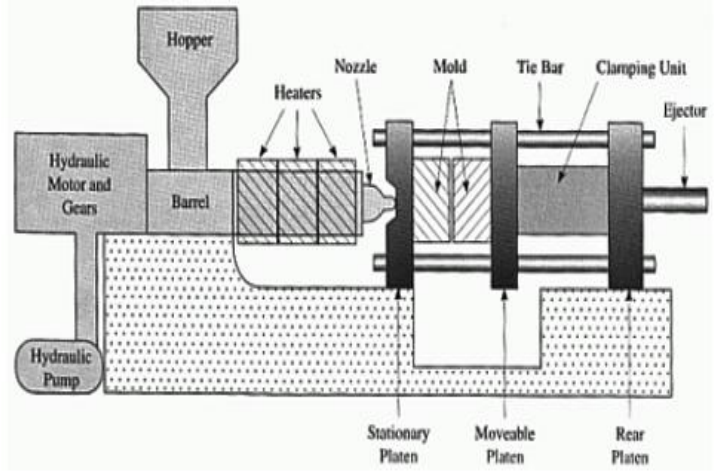

Gambar 1. Bagian-bagian injection molding

Berikut ini adalah penjelasan beberapa komponen utama pada injection molding: Hopper bagian yang berfungsi untuk menempatkan material di mesin. Barrel merupakan tempat untuk pemrosesan material (mengubah material padat menjadi cair) sebelum di injeksi ke mold (cetakan). Nozzle adalah bagian dari mesin yang berfungsi untuk menginjeksikan plastik ke dalam mold (cetakan). Tie Bar digunakan sebagai penyangga untuk mold, clamping, dan ejector. Hydraulic Motor berfungsi untuk mendorong screw pada saat injeksi dan memutar screw pada saat pengisian material atau disebut plasticizing supaya bijih plastik mencair. Stationary platen adalah plate yang tidak bergerak (diam) sebagai tempat locating ring pada saat menaikkan tooling. Moveable platen adalah plate yang bergerak dengan arah maju dan mundur pada saat beroperasi atau produksi. Clamping unit adalah bagian yang berfungsi untuk membuka dan menutup mold pada saat beroperasi atau produksi. Ejector adalah berfungsi sebagai pendorong produk yang sudah tercetak. Rear platen bagian yang berfungsi sebagai plate penyangga bagian belakang.[1]

Dalam pengerjaan dengan injection molding susunan proses yang terjadi adalah sebagai berikut: Termoplastik dalam bentuk butiran dimasukan melalui sebuah hopper kemudian material turun dan masuk kedalam barrel secara otomatis (karena gaya gravitasi) di dalam barrel terjadi pemanasan dengan menggunakan temperatur yang di hasilkan oleh dinding barrel sehingga material meleleh, material yang sudah meleleh kemudian di injeksikan oleh screw menuju mold (cetakan) melalui nozzle, pada mold tersebut material akan di beri temperatur pendingin agar material me- ngeras. Material yang sudah mendingin dan mengeras di keluarkan dari mold dengan dorongan hidraulik.

Pada proses produksi dengan menggunakan mesin injection molding tidak terhindar dari berbagai masalah defect atau reject pada produk yang dihasilkan. Beberapa defect yang biasa timbul diantaranya adalah shot molding, flashing, black dot, crack line, sink mark, dented, crack, hight getting, dan bubble pada bagian tertentu. Reject crack line adalah suatu reject yang timbul dikarenakan meningkatnya temperatur media pendingin dan tidak sesuainya penggunaan circle time yang menyebabkan waktu pendinginan tidak sesuai dengan kondisi material yang akan di keraskan. Circle time adalah waktu yang dibutuhkan dalam proses injeksi material kedalam mold (cetakan) melalui nozzle ditambah dengan colling time (waktu pendinginan) atau pengerasan produk.

Tujuan penelitian ini adalah mengetahui efek temperature media pendingin dan circle time pada proses injection molding produk Sp 04 Haemonetics.

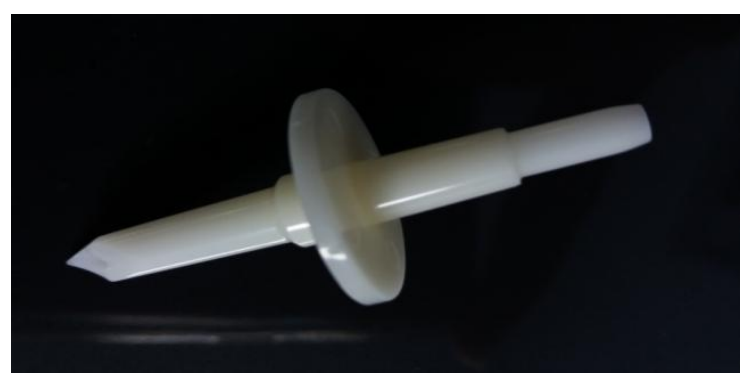

Gambar 2. Produk Sp 04 Haemonetics.

Batasan masalah dalam penelitian ini yaitu penelitian dilakukan pada mesin injection molding NISSEI ES1000 dan dengan menggunakan material ABS TECHNO 330.

\section{Metodologi Penelitian}

Penelitian ini dilakukan dengan cara pengujian secara langsung terhadap produk SP 04 Haemonetics dimana produk tersebut adalah produk hasil produksi mesin injection molding yang menggunakan material $A B S$ TECHNO 330 dengan temperature pada molding $80^{\circ} \mathrm{C}$.

Mesin yang digunakan sebagai alat pengujian adalah Injection Molding NISSEI ES1000 dengan spesifikasi pada tabel 1.[2]

Tabel 1. Spesifikasi injection molding NISSEI ES1000

\begin{tabular}{|c|c|c|}
\hline Merk Brand & $:$ & NISSEI \\
\hline Type & $:$ & ES1000 \\
\hline Injection Type & $:$ & $12 \mathrm{E}$ \\
\hline Screw Diameter & $:$ & $32 \mathrm{~mm}$ \\
\hline Clamping force & $:$ & $80 \mathrm{Ton}$ \\
\hline
\end{tabular}




\begin{tabular}{|c|c|c|}
\hline Min Mold Thickness & $:$ & $200 \mathrm{~mm}$ \\
\hline Max Mold Thickness & $:$ & $300 \mathrm{~mm}$ \\
\hline Colling & $:$ & Water \\
\hline Diameter Screw & $=$ & $32 \mathrm{~mm}$ \\
\hline Mold Dimension & $=$ & $400 \times 400 \times 300 \mathrm{~mm}$ \\
\hline Temperature Colling & $=$ & $19^{0}$ \\
\hline $\begin{array}{c}\text { Maximum Daylight } \\
\text { (Opening) }\end{array}$ & $=$ & $670 \mathrm{~mm}$ \\
\hline
\end{tabular}

Material yang digunakan sebagai bahan penelitian adalah ABS TECHNO 300 . ABS TECHNO 330 adalah salah satu dari jenis material ABS (Acrylonitrile Butadiene Styrene) dimana material ini merupakan sejenis polimer yang memiliki spesifikasi melting point sebesar $80^{\circ} \mathrm{C}$ dan Tensile Strength $43 \mathrm{M} \mathrm{Pa}$.

Sistem pengujian dilakukan dengan variasi temperatur media pendingin cetakan (mold) yang menggunakan air yang di dinginkan dengan menggunakan chiller water (mesin pengubah suhu air) dan variasi circle time mesin injection molding. Pada penelitian tersebut dilakukan tiga kali proses menggunakan variasi temperatur yaitu $19^{\circ} \mathrm{C}, 20^{\circ} \mathrm{C}, 21^{\circ} \mathrm{C}, 22^{\circ} \mathrm{C}$ dan $23^{\circ} \mathrm{C}$, dan pada setiap penggunaan temperature maka akan diberi pengujian circle time yaitu 13 detik, 15 detik, 17 detik, 19 detik dan 21 detik.

Setiap hasil proses produksi yang bevariasi tersebut akan di cek dan diukur menggunakan Smartscope (alat pengukur yang menggunakan prinsip kerja seperti mikroskop hanya saja pada alat ini menggunakan komputer sebagai media menampilkan gambaran benda yang di ukur dan pada Smartscope pengukuran tidak hanya pada panjang melainkan dapat juga mengukur radius, mengukur diameter dan menentukan titik pusat suatu benda). Untuk menentukan reject atau accept produk SP 04 Haemonetics dari defect crack line dapat dilakukan dengan pengukuran menggunakan alat ukur Smartscope, apabila ditemukan crack line pada permukaan maka produk tersebut dinyatakan reject dan tanpa crack line pada permukaan produk tersebut dinyatakan accept.

Alat yang digunakan untuk pengukuran reject crack line pada produk Sp 04 Haemonetics adalah SmartScope.

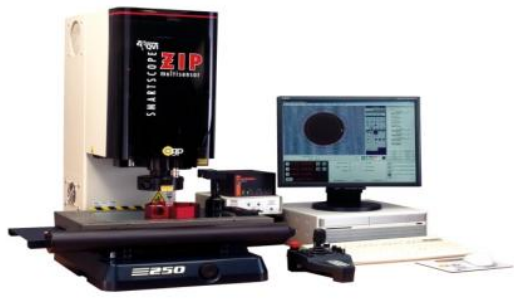

Gambar 3. Alat ukur Smartscope. [4]
Berikut ini adalah contoh pengukuran crack line pada produk Sp 04 Haemonetics dengan menggunakan Alat ukur Smartscope.

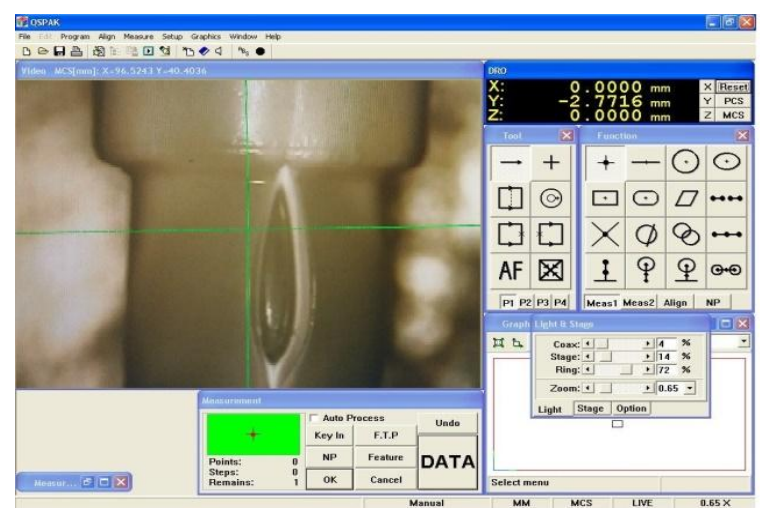

Gambar 4. Tampilan pengukuran dengan alat Smartscope.

\section{Analisa Dan Pembahasan}

Setelah melakukan pengujian secara langsung pada proses produksi produk $\mathrm{Sp} 04$ Haemonetics dengan variasi temperatur $19^{\circ} \mathrm{C}, 20^{\circ} \mathrm{C}, 21^{\circ} \mathrm{C}, 22^{\circ} \mathrm{C}$ dan $23^{\circ} \mathrm{C}$ dengan penggunaan circle time pada setiap temperatur yang bervariasi yaitu 13 detik, 15 detik, 17 detik, 19 detik dan 21 detik maka didapatkan hasil pengukuran panjang dan lebar maksimal defect crack line sebagai berikut :

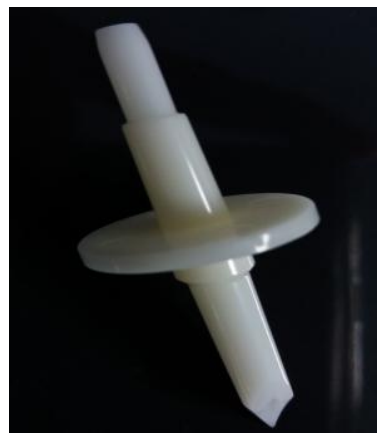

Gambar 5. Hasil pengujian dan pengukuran defect crack line pada Sp 04 Haemonetics dengan temperatur media pendingin $19^{\circ} \mathrm{C}$

Pada gambar 5 diperlihatkan hasil pengujian proses injeksi molding dengan menggunakan temperatur media pendingin $19^{\circ} \mathrm{C}$ dimana pada penggunaan temperatur ini tidak terdapat reject crack line baik dengan circle time 13 detik, 15 detik, 17 detik 19 detik, dan 21 detik.

Pada gambar 6 diperlihatkan hasil pengujian yang mengalami kerusakan crack line pada pengujian dengan temperatur $20^{\circ} \mathrm{C}$ dan circle time 13 detik dimana pada proses ini produk mengalami kerusakan dengan panjang dan lebar maksimal crack line adalah 7.8 × 0.7 $\mathrm{mm}$. 


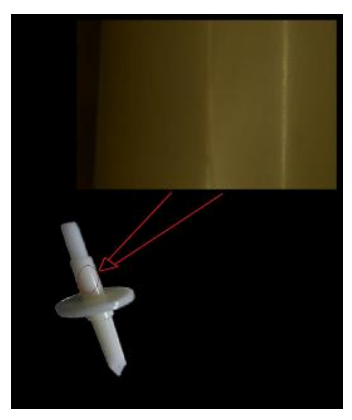

Gambar 6. Hasil pengujian dan pengukuran defect crack line pada Sp 04 Haemonetics dengan temperatur media pendingin $20{ }^{\circ} \mathrm{C}$ dengan perbesaran gambar $100 \%$
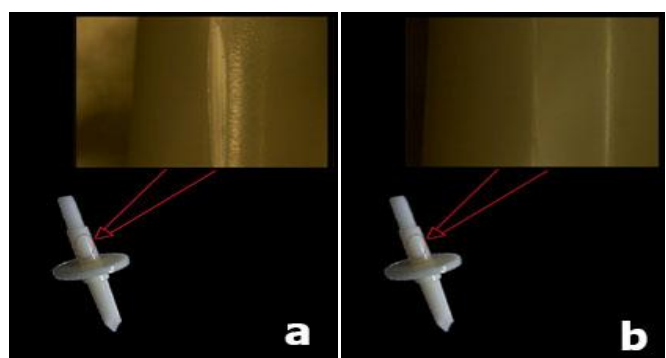

Gambar 7. Hasil pengujian dan pengukuran defect crack line pada Sp 04 Haemonetics dengan temperatur media pendingin $21{ }^{\circ} \mathrm{C}$ dengan perbesaran gambar $100 \%$.

Pada gambar 7 diperlihatkan hasil pengujian dengan temperatur media pendingin $21{ }^{\circ} \mathrm{C}$ mengalami masalah reject crack line dengan circle time berbeda yaitu (a) proses pengujian dengan circle time 13 detik dimana pada proses ini pada produk terdapat reject crack line dengan panjang dan lebar maksimal 10.8 x $0.38 \mathrm{~mm}$ dan (b) proses pengujian dengan circle time 15 detik dimana pada proses ini terdapat reject crack line dengan panjang dan lebar maksimal 7.8 x $0.8 \mathrm{~mm}$.

Gambar 8 memperlihatkan bahwa pada pengujian dengan tempertur media pendingin $22^{\circ} \mathrm{C}$ mengalami masalah reject crack line dengan circle time yang berbeda yaitu (a) proses pengujian dengan circle time 13 detik dimana pada proses ini pada produk terdapat reject crack line dengan panjang dan lebar maksimal $13.7 \times 0.89 \mathrm{~mm}$, (b) proses pengujian dengan circle time 15 detik dimana pada proses ini pada produk terdapat reject crack line dengan panjang dan lebar maksimal 11.4 x $0.39 \mathrm{~mm}$ dan (c) proses pengujian dengan circle time 17 detik dimana pada proses ini pada produk terdapat reject crack line dengan panjang dan lebar maksimal 8.1 x $0.10 \mathrm{~mm}$.
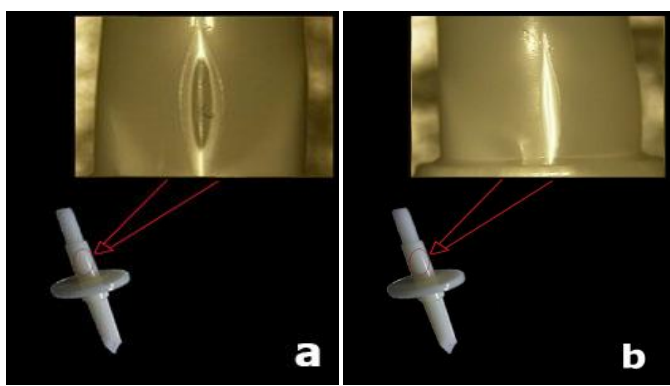

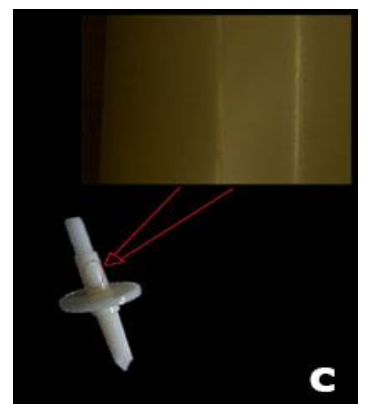

Gambar 8. Hasil pengujian dan pengukuran defect crack line pada $\mathrm{Sp} 04$ Haemonetics dengan temperatur media pendingin $22^{\circ} \mathrm{C}$ dengan perbesaran gambar $100 \%$.

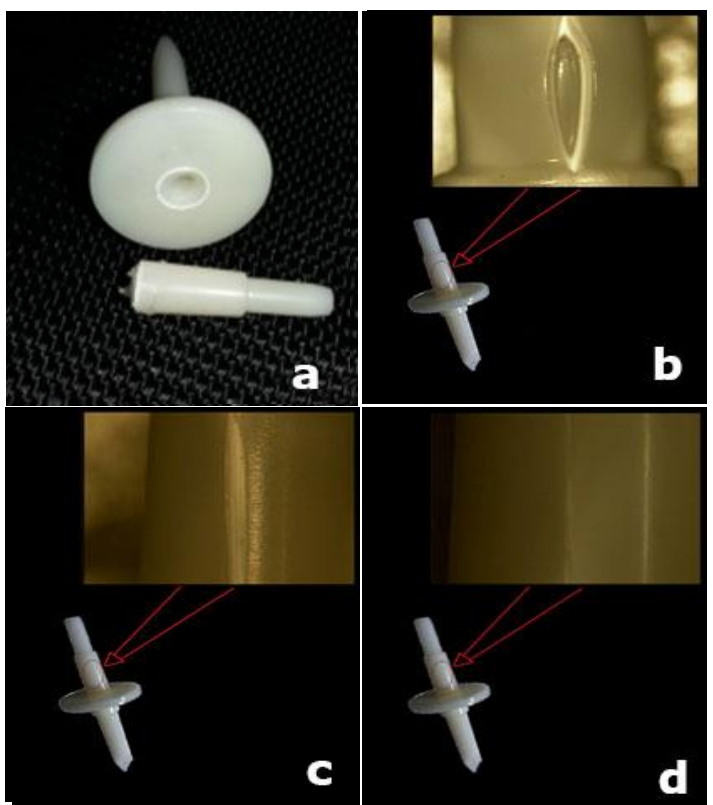

Gambar 9. Hasil pengujian dan pengukuran defect crack line pada Sp 04 Haemonetics dengan temperatur media pendingin $23^{\circ} \mathrm{C}$ dengan perbesaran gambar $100 \%$

Pada gambar 9 di jelaskan bahwa pengujian dengan temperatur media pendingin $23^{\circ} \mathrm{C}$ mengalami reject crack line dengan circle time yang berbeda yaitu (b) proses pengujian dengan circle time 15 detik dimana pada proses ini pada produk terdapat reject crack line dengan panjang dan lebar maksimal 13.8 x $0.91 \mathrm{~mm}$, (c) proses pengujian dengan circle time 17 detik dimana pada proses ini pada produk terdapat reject crack line dengan panjang dan lebar maksimal 11.36 x $0.39 \mathrm{~mm}$, dan (d) proses pengujian dengan circle time 19 detik dimana pada proses ini pada produk terdapat reject crack line dengan panjang dan lebar maksimal $8.1 \mathrm{x}$ $0.11 \mathrm{~mm}$ serta (a) merupakan reject broken (patah) proses pengujian dengan circle time 13 detik.

Dari hasil pengujian sebagaimana dijelaskan di atas, ditemukan ukuran panjang crack line yang terjadi pada produk Sp 04 Haemonetics. Dan dari pengujian ditemukan solusi untuk pencegahan crack line pada $S p 04$ Haemonetics dengan penyesuaian temperatur media 
pendingin dengan circle time sebagai berikut :

Tabel 2. Penggunaan circle time berdasarkan temperatur media pendingin.

\begin{tabular}{|c|c|c|}
\hline No. & $\begin{array}{c}\text { Temperatur } \\
\text { Media Pendingin }\end{array}$ & Circle Time \\
\hline 1. & $19{ }^{\circ} \mathrm{C}$ & $13,15,17,19,21$ detik \\
\hline 2. & $20^{\circ} \mathrm{C}$ & $15,17,19,21$ detik \\
\hline 3. & $21{ }^{\circ} \mathrm{C}$ & $17,19,21$ detik \\
\hline 4. & $22{ }^{\circ} \mathrm{C}$ & 19,21 detik \\
\hline 5. & $23{ }^{\circ} \mathrm{C}$ & 21 detik \\
\hline
\end{tabular}

Melalui tabel diatas dapat di simpulkan bahwa temperatur media pendingin dan circle time yang optimal digunakan pada saat proses produksi produk $S p 04$ Haemonetis adalah $19^{\circ} \mathrm{C}$ dengan circle time 13 detik karena dengan penggunaan circle time 13 detik pada temperatur media pendingin $19^{\circ} \mathrm{C}$ akan mempercepat proses produksi tanpa menimbulkan defect. Dan pada penggunaan temperatur media pendingin yang lebih besar dari dapat menggunakan penyesuaian circle time yang optimal sesuai tabel berikut:

Tabel 3. Penyesuaian circle time yang optimal pada setiap tingkatan temperatur media pendingin.

\begin{tabular}{|c|c|c|}
\hline No. & $\begin{array}{c}\text { Temperatur } \\
\text { Media Pendingin }\end{array}$ & Circle Time \\
\hline 1. & $19^{\circ} \mathrm{C}$ & 13 detik \\
\hline 2. & $20^{\circ} \mathrm{C}$ & 15 detik \\
\hline 3. & $21{ }^{\circ} \mathrm{C}$ & 17 detik \\
\hline 4. & $22{ }^{\circ} \mathrm{C}$ & 19 detik \\
\hline 5. & $23{ }^{\circ} \mathrm{C}$ & 21 detik \\
\hline
\end{tabular}

\section{Kesimpulan}

Dari penelitian mengenai pengaruh temperatur media pendingin terhadap defect crack line pada produk Sp 04 Haemonetics dapat disimpulkan bahwa :

1. Semakin tinggi temperatur media pendingin yang digunakan maka semakin lama proses pendinginan (pengerasan) produk yang dibutuhkan dengan demikian untuk menghindari defect crack line dibutuhkan penambahan circle time.

2. Semakin tinggi circle time yang digunakan dapat mengurangi panjang dan lebar defect crack line.

Setelah mengetahui pengaruh temperatur pendingin dan circle time terhadap defect crackline pada produk yang dihasilkan maka penelitian lanjutan yang cukup menarik untuk dilakukan adalah pengaruh jenis media pendingin yang digunakan terhadap kualitas hasil produksi moulding. Jenis media pendingin tersebut bisa berupa air, air distilasi maupun oli.

\section{Ucapan Terima Kasih}

Penulis ucapkan banyak terima kasih kepada Bapak Yudi Harsono selaku Engineer di PT. Honfoong Plastik yang selama ini sudah mendukung saya dalam penyusunan artikel ilmiah ini dimana telah memberikan saya banyak masukan ilmu dan menyediakan saya fasilitas di PT. Honfoong Plastik untuk melakukan penelitian produk SP 04 Haemonetics.

\section{Referensi}

[1] Nurahmi, Latifah. 2009. Studi Simulasi Pengaruh Temperature Injeksi, Tekanan Holding, Dan Pendinginan Terhadap Pembentukan Sink Mark Pada Proses Plastic Injection Moulding. Surabaya : ITS

[2] Sakaki, Machi. 2000. Nissei Instruction Manual. Nagano-ken : Nissei Plastic Industrial Co., LTD.

[3] 2015. Iso Techno Plastics Guide : TechnoPolymer Co., LTD

[4] OPTICAL GAGING (M) SDN BHD (C). 2014. OGP Smartscope ZIP 250/250E. http://www.smartscope.com.my/products/ogp-sm artscope-zip-/3-ogp-smartscope-zip-250---250e. 10 Mei 2016 